\title{
Study regarding the structural response of standard cylindrical roller bearings using ANSYS and MESYS
}

\author{
Alin Marian Pușcașu*, Octavian Lupescu and Ana Bădănac \\ Technical University "Gheorghe Asachi” of Iasi-Romania, Department of Machine Manufacturing \\ Technology, Blvd. Mangeron, No. 59A, 700050, Iasi, Romania
}

\begin{abstract}
Bearings are manufactured in a wide variety of types and sizes especially with a single row of rollers, two rows of rollers or more, with cages or roller beside roller. Researches carried out by authors in this paper have followed a comparative analysis between a standard cylindrical roller bearings design and a prototype design using finite element method software's like ANSYS and MESYS. ANSYS is commonly used and enjoyed by an extended use in the structural areas, for analysis. ANSYS it consists of three main phases: Pre-processing, conducting or importing of the solid model system that are to be analyzed, solid meshing design in finite elements, implementation of conditions and loads at the limit, Processing, numeric solving of the characteristic equations behavior of the system and getting the solution, Post-processing, viewing the results in order to analyses system reaction and identification of areas with critical applications. The purpose of the study was to collect data's using two different software's and after to compare them with mathematical results. Using the ANSYS in this purpose it was able to analyses the design of the structure of the cylindrical roller bearing in detail.
\end{abstract}

\section{Introduction}

The bearings industry began to use remarkable technological advancement to improve products quality. Optimization of standard construction, improving the calculation methods and testing have provided high quality product with low cost.

Bearings are generally made of two rings or washers, a number of rolling elements and a cage. The inner and outer rings are used in radial bearings, while the washers (thrust and housing) are meet at thrust bearings.

The rolling elements (balls or roller) are in direct contact with those two rings through the raceways. Through means that rings or washers are performed the direct connection of the bearing with the assembly in which it is mounted; the inner ring it is mounted on the shaft and the outer ring is fitted in the housing. The cage has the purpose to maintain fixed distances between rolling elements and also to hold them. There are bearing constructions in which it might be missing one or more components. Thus there are bearings without the

*Corresponding author: puscasu_alin@yahoo.com 
one ring or both rings; in this case the raceways are made directly on the shaft or/and on the housing. Also there are bearings that may be without cage, [1].

ANSYS simulation software allows the designer to predict how the product will work under real conditions. Simulation is a powerful modular system.

Simulation-Driven Product Development Product brings simulation to another level. ANSYS adds value by providing the design process efficiency, encouraging innovation and reducing physical constraints, allowing simulated tests that might not be possible otherwise. It is unmatched in functionality and power needed to optimize components and systems.

The rolling bearing analysis software MESYS calculates the life of rolling bearings according ISO/TS 16281 considering the inner geometry of the bearing. Considering the load distribution within the bearing, clearance and tilting angle will affect the resulting bearing life.

The inner geometry of the rolling bearing is provided by the user, but it can also be approximated from the load capacities by the software. The calculation returns the pressure distribution between the rolling elements and the reference life according ISO/TS 16281 for a given loading (force and moment or tilting). A simplified calculation of a deep groove ball bearing is also available online.

In addition to the calculation of a single bearing also bearing sets can be considered. Examples would be a set of angular contact bearings, an eight-point bearing for a slewing ring as combination of two four point bearings or a combination of cylindrical roller bearings in a planetary gear.

Incorporating world leading software capabilities of PTC Creo product design, RULMENTI S.A. Barlad uses ANSYS functionality even further to ensure and to obtain the fairest solution in the shortest time.

ANSYS Mechanical is a comprehensive tool for analysis FEA structural type analysis, including linear and nonlinear dynamic studies. The product offers a complete set of elements, material models and equation solving a wide range of mechanical design problems [2].

ANSYS Mechanical includes expanded capabilities for solving dynamic, including modal analysis for calculating the natural frequencies and mode shapes, harmonic analysis to determine its harmony which varies over time depending on load transient nonlinear dynamic analysis and random vibration spectrum analysis. Behavioral characterization of the material is intuitive mathematical models using library materials, regardless of their structure, [3-4].

Because complex systems are made of several parts, ANSYS tools enable to be captured critical interactions between them. Whether using contacts, special connections or joints that define the relationship between body's cinematic solutions lead to insight into the complex interactions. Its parametric capabilities to help you effectively perform sensitivity studies or optimization.

\section{Method}

For the study of the structural response between a standard cylindrical roller bearing (Figure 1) and a prototype cylindrical roller bearing it was used two different methods, the static structural benchmarks and contact stress analysis.

For ANSYS the geometry was prepared before importation. After that the geometry is checked for errors, the elements are meshed the load and constrains are established after the analysis is run. This method consists of a continuous body mesh and finished in several finite elements (FEM - Finite element method).

For MESYS it was enough to establish the type of bearing, number of elements and data's about the dimensions and load conditions. 


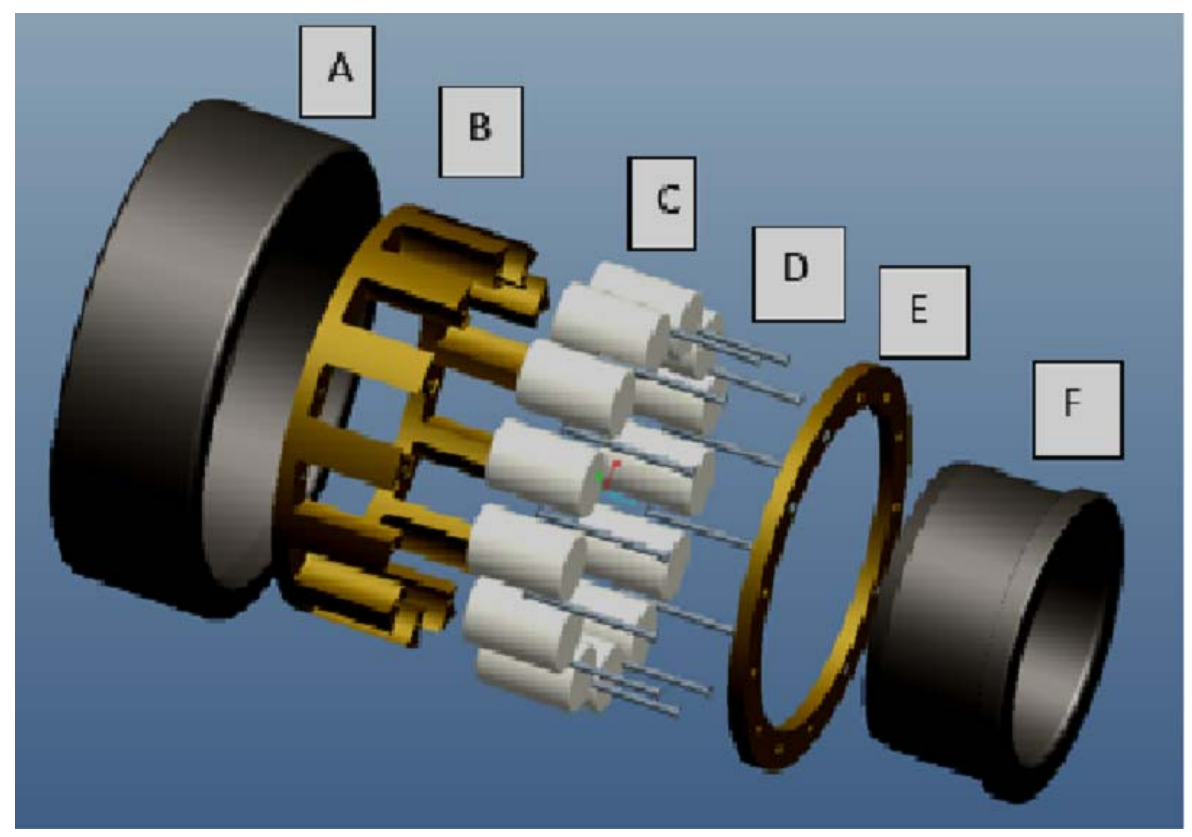

Fig. 1. Cylindrical roller bearings type $\mathrm{NJ}$ with cage EMA.
$A$ : outer ring
$B$ : cage type $\mathrm{M}$
$C$ : rollers
$D$ : rivets
E: cap cage
$F$ : inner ring

The finite element programs in our case ANSYS 17.0 and MESYS are holding a library of hundreds of types of elements and finite elements.

First it has achieved a 3D model using CREO Parametric 3.0, then was analyzed using ANSYS software and then with MESYS.

For performing experimental researches was used cylindrical roller bearings type NJ2317 EMA presented in Figure 1 and prototype. Was performed a mechanical and a contact stress analysis.

Boundary conditions were established that the bearing is subjected respectively declared as moving from fixed and limiting axial displacements.

It was subject to the following conditions of simulation:

- The boundary conditions are identical to those of the static structural analysis;

- The outer ring are constrained in all degrees of freedom.

- Load bearing is applied through the shaft.

- Load levels are: $1200 \mathrm{rpm}$ rotational speed respectively $80 \mathrm{kN}$ radial load.

\section{Results}

At this stage the results obtained with the ANSYS software and the results obtained with the MESYS software were compared to observe the differences and similarities.

At the same time, a series of calculations were carried out according to the URB catalog in order to check the mathematical results, as in Table 1. 
Table 1. The results obtained with the ANSYS and MESYS software.

\begin{tabular}{|c|c|c|c|c|}
\hline \multicolumn{2}{|r|}{ Products analyzed } & $\begin{array}{l}\text { NJ2317 EMA } \\
\text { (ANSYS) }\end{array}$ & $\begin{array}{l}\text { NJ2317 EMA } \\
\text { (MESYS) }\end{array}$ & Differences \\
\hline \multirow{2}{*}{$\begin{array}{c}\text { Loading } \\
\text { conditions }\end{array}$} & Rotation speed & $1200 \mathrm{Rpm}$ & $1200 \mathrm{Rpm}$ & \multirow{2}{*}{$\%$} \\
\hline & Load force & $80 \mathrm{kN}$ & $80 \mathrm{kN}$ & \\
\hline Nr. Crt. & \multicolumn{4}{|c|}{ Results } \\
\hline 1 & $\begin{array}{c}\text { Von-Mises equivalent } \\
{[\mathrm{MPa}]}\end{array}$ & 1100 & 1200 & $\uparrow 8.3 \%$ \\
\hline 4 & $\begin{array}{l}\text { The maximum value of the } \\
\text { inner ring shear tension } \\
{[\mathrm{MPa}]}\end{array}$ & 449 & 504.93 & $\uparrow 11 \%$ \\
\hline 5 & $\begin{array}{l}\text { The maximum value of the } \\
\text { outer ring shear tension } \\
{[\mathrm{MPa}]}\end{array}$ & 630 & 420.013 & $\downarrow 32 \%$ \\
\hline 6 & $\begin{array}{c}\text { Contact pressure } \\
{[\mathrm{MPa}]}\end{array}$ & 395,8 & 400,25 & $\uparrow 1 \%$ \\
\hline 7 & $\begin{array}{c}\text { Life } \\
\text { [cycles] }\end{array}$ & 186.23 & 160.418 & $\uparrow 13.5 \%$ \\
\hline 8 & $\begin{array}{l}\text { Safety factor } \\
\quad \mathrm{Sf}<1.5\end{array}$ & 2.09 & 5.6 & $\uparrow 60.5 \%$ \\
\hline
\end{tabular}

The final calculation of the bearing life and safety factor is given by equation (1) and (2) respectively equation (3):

$$
L_{10}=\left(\frac{c}{p}\right)^{p}=\left(\frac{367}{80}\right)^{\frac{10}{3}}=159.60
$$

Where,

$C=367 \mathrm{kN}$

$P=80 \mathrm{kN}$

$$
\begin{gathered}
L_{10 h}=\left(\frac{1000000}{60 * 1200}\right) *\left(\frac{367}{80}\right)^{\frac{10}{8}}=2216.6 \mathrm{~h} \\
S_{0}=\frac{c_{r_{0}}}{P_{r_{\theta}}}=\frac{475.123}{80}=5.9
\end{gathered}
$$

Where,

$C_{r 0}=$ basic static load

$P_{r 0}=$ equivalent static load

$S_{0}=$ static safety factor

In Figure 2 there are shown the analysis results on the contact stress on rollers and rings. 
In Figure 3 it is shown the bearing life and the resulted value is approximately near the value determined using formulas from ISO 281, [4]. The graphs of the results contact stress on roller and rings are shown in Figure 4.

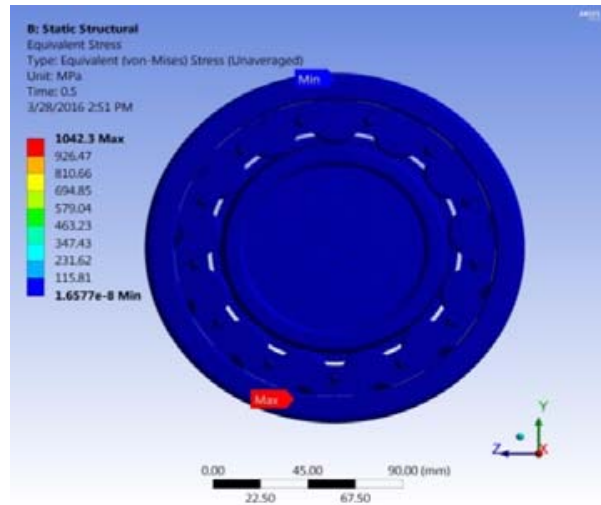

a) Frontal view

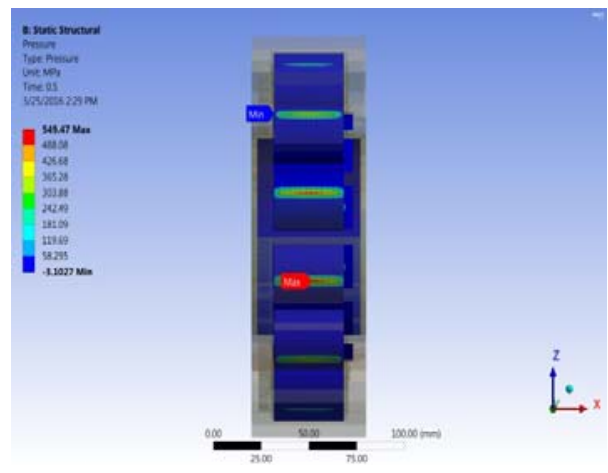

c) Side view

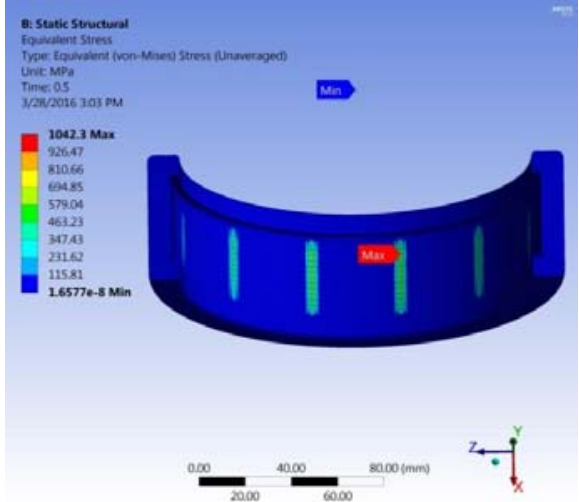

b) Contact zone

\begin{tabular}{|c|c|}
\hline \multicolumn{2}{|c|}{ Integration Point Results } \\
\hline Display Option & Unaveraged \\
\hline \multicolumn{2}{|l|}{ Results } \\
\hline$\square$ Minimum & $1.6577 \mathrm{e}-008 \mathrm{MPa}$ \\
\hline$\square$ Maximum & $1042.3 \mathrm{MPa}$ \\
\hline Minimum Occurs On & Outer ring \\
\hline Maximum Occurs on & RC-26×40-LN[555] \\
\hline \multicolumn{2}{|c|}{ Minimum Value Over Time } \\
\hline Minimum & $1.5639 \mathrm{e}-009 \mathrm{MPa}$ \\
\hline Maximum & $1.6577 \mathrm{e}-008 \mathrm{MPa}$ \\
\hline \multicolumn{2}{|c|}{ Maximum Value Over Time } \\
\hline$\square$ Minimum & $194.31 \mathrm{MPa}$ \\
\hline$\square$ Maximum & $1042.3 \mathrm{MPa}$ \\
\hline Information & \\
\hline
\end{tabular}

d) Analysis results

Fig. 2. The analysis results on the contact stress on rollers and rings.

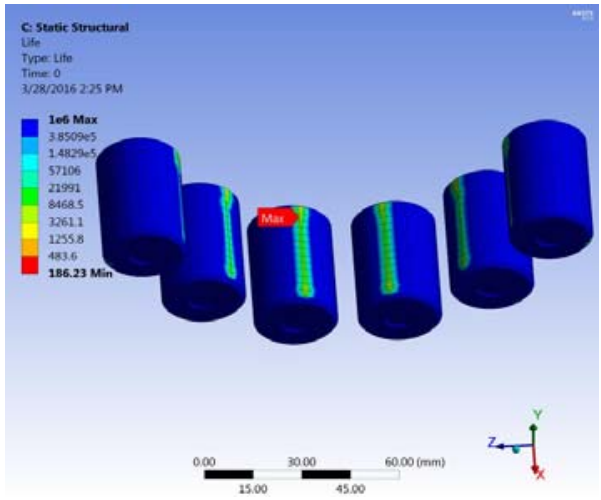

a) The life of the rollers

\begin{tabular}{|c|c|}
\hline \multicolumn{2}{|l|}{ Scope } \\
\hline Scoping Method & Geometry Selection \\
\hline Geometry & All Bodies \\
\hline \multicolumn{2}{|l|}{ Definition } \\
\hline Type & Life \\
\hline \multicolumn{2}{|l|}{ Identifier } \\
\hline Suppressed & No \\
\hline \multicolumn{2}{|l|}{ Integration Point Results } \\
\hline Average Across Bodies & No \\
\hline \multicolumn{2}{|l|}{ Results } \\
\hline Minimum & 186.23 cycles \\
\hline Minimum Occurs on & NU2317EMA-10[157] \\
\hline
\end{tabular}

b) Analysis results

Fig. 3. Results of the analysis bearing life. 


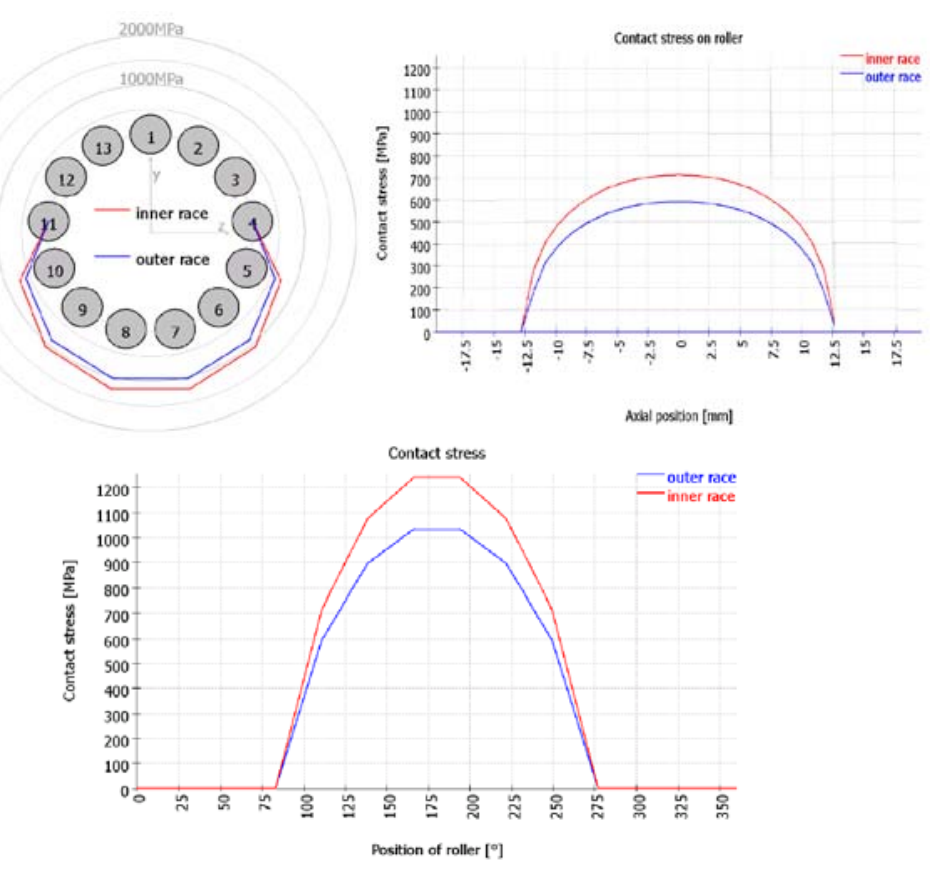

Fig. 4. The graphs of the results contact stress on roller and rings.

\section{Conclusions}

Analyze of the results led to the following conclusions: the observed differences may be due to the fact that MESYS does not take into account the presence of the cage; at the same time, ANSYS does not take into account the roughness of the surfaces.

Using two different methods of analyzing the bearing ANSYS and MESYS help us to get more exact data that can be used to improve the geometry and the characteristics of the next generation products.

\section{References}

1. M. Gafiteanu, D. Nastase, S. Cretu, D. Olaru, Rolling Bearings, Design and technology, vol 1 (in Romanian) (Ed. Tehnica, Bucuresti, 1985)

2. P. Chunjun, Thesis of Static Analysis of Rolling Bearings Using Finite Element Method (May 2009)

3. Z. Yongqi, T. Qingchang, Z. Kuo1, L. Jiangang, Analysis of Stress and Strain of the Rolling Bearing by FEA method, International Conference on Applied Physics and Industrial Engineering. Physics, 24 (2012)

4. International Standard, Rolling Bearings - dynamic load rating and rating life, ISO 281 (2007) 